\title{
Assessing Stigma Towards Chronic Insomnia: The Role of Health Status and Life Quality
}

Shuo He

Chaohu Hospital of Anhui Medical University

Xue-Jia Ke

Chaohu Hospital of Anhui Medical University

Yan Wu

Chaohu Hospital of Anhui Medical University

Xiao-Yi Kong

Chaohu Hospital of Anhui Medical University

Ping Zhang

Chaohu Hospital of Anhui Medical University

Yun Wang

Chaohu Hospital of Anhui Medical University

Deng-Zhi Xia

Chaohu Hospital of Anhui Medical University

Hui-Qin Sun

Chaohu Hospital of Anhui Medical University

Gui-Hai Chen ( $\nabla$ doctorcgh@163.com )

Chaohu Hospital of Anhui Medical University

Research

Keywords: health status, insomnia, mental health, quality of life, stigma

Posted Date: September 20th, 2021

DOI: https://doi.org/10.21203/rs.3.rs-861035/v1

License: (9) (1) This work is licensed under a Creative Commons Attribution 4.0 International License. Read Full License 


\section{Abstract \\ Background}

The objective of this study was to explore the stigma and related influencing factors in patients with chronic insomnia disorder (CID).

\section{Methods}

A total of 70 CID patients and 70 healthy controls (CON) were enrolled in the study. The Pittsburgh Sleep Quality Index (PSQI) and the 17-Item Hamilton Depression Rating Scale (HAMD-17) were used to assess sleep quality and depressive symptoms, respectively. The Chinese-Beijing version of the Montreal Cognitive Assessment scale (MoCA-C) was used to assess cognitive function. Stigma and life quality were measured using the Chronic Stigma Scale and the 36-Item Short-Form Health Survey (SF-36).

\section{Results}

The ratio of individuals with stigma was significantly different between $\mathrm{CID}$ and $\mathrm{CON}$ groups $\left(\mathrm{C}^{2}=35.6, p<0.001\right)$. Compared with the CON group, the CID group had higher scores for total stigma $(U=662.0, p<0.001)$, internalized stigma $(U=593.0, p<0.001)$, enacted stigma $(U=1568.0, p<0.001)$, PSQI $(U=$ 2485.0, $p<0.001)$ and HAMD-17 $(U=69.5, p<0.001)$ as well as lower scores for MoCA-C $(U=3997.5, p<0.001)$ and SF-36 for the items of physical role $(U=$ $1560.5, p<0.001)$, body pain $(U=1633.5, p<0.001)$, general health $(U=1194.0, p<0.001)$, vitality $(U=1169.5, p<0.001)$, social function $(U=1703.0, p=$ 0.001), emotional role $(U=1451.5, p<0.001)$, mental health $(U=1147.0, p<0.001)$ and health transition $(U=1341.0, p<0.001)$. Partial correlation analysis showed that different items of the Chronic Stigma Scale were positively correlated with illness duration, PSQI and HAMD-17 scores, while negatively correlated with one or more items of the SF-36. Multivariate regression analysis showed that illness duration and the mental health domain of the SF-36 were independent risk factors for one or more items of stigma in CID patients.

\section{Conclusion}

Patients with CID have an increased risk of stigma. Moreover, illness duration and mental health may be primary factors related to stigma.

\section{Introduction}

Stigma manifests as both prejudice of and rejection from society towards patients who suffer from a specific pathology. A patient's internalization of such discrimination can have repercussions on their state of mind and quality of life. ${ }^{1}$ It is possible to distinguish between "enacted stigma", which consists of actual discrimination and rejection by society towards the patient, and "internalized stigma", whereby the patient becomes aware of the discrimination and internalizes the negative impact of their disease. ${ }^{2}$ Different degrees of stigma seriously affect physical health conditions, which can subsequently exacerbate mental health conditions and further harm an individual's health. ${ }^{3}$ Additionally, mental disorders have been reported to accompany stigmatization, which results in increased psychological distress and decreased health-related quality of life. ${ }^{4}$

Depression is a common mental health disorder, with more than 300 million people affected worldwide; one of the barriers to treatment is social stigma. ${ }^{5}$ Despite the high personal burden for individuals with depression, not all individuals seek professional treatment, and an increasing number of studies globally have shown that stigma is a barrier to individuals seeking help. ${ }^{6-8}$ Insomnia is not only a risk factor for depression but also a frequent complaint of patients with depression. ${ }^{9-11}$ Symptoms of insomnia are considered a critical feature of mental disorders, and a better understanding of the processes involved can contribute to the refinement of pathophysiological concepts and therapeutic approaches for depressive disorders. ${ }^{12}$ Research has shown that increased stress and depressive symptoms are closely associated with weight stigma in adolescents, which can result in poorer global sleep quality and more daytime dysfunction. ${ }^{13}$ However, despite the high comorbidity of depression and insomnia, ${ }^{14}$ the role that stigma plays in chronic insomnia disorder (CID) remains unclear.

This study aimed to better understand: 1) the risk of stigma in patients with CID and 2) related influencing factors of stigma in CID patients. Our study may contribute to the knowledge gap regarding chronic insomnia stigma and offer a better understanding of the experiences of individuals with sleep disorders who experience stigma.

\section{Methods}

\subsection{Subjects}

A total of 70 CID patients were recruited from the Clinic of Sleep and Memory Disorder of the Affiliated Chaohu Hospital of Anhui Medical University between September 2019 and June 2020. In addition to meeting the International Classification of Sleep Disorders, Third Edition (ICSD-3) diagnostic criteria for CID, ${ }^{15}$ inclusion criteria for patients were as follows: (1) aged between 18 and 75 years; (2) had at least 6 years of education without problems in comprehension; (3) not taking drugs that could potentially interfere with sleep, cognitive function or endocrine function in the 3 months prior to enrolment; and (4) voluntarily participating in the study after providing written informed consent. Exclusion criteria were as follows: (1) somatic comorbidity (including immunologic, 
endocrine, cardiovascular, neurologic, liver, kidney or organic brain disease); (2) history of substance abuse; (3) recent infection or inflammation (within 2 weeks of the start of the study); (4) taking drugs that could affect sleep, mood, immune function or cognition; and (5) pregnant or lactating women.

We also recruited 70 healthy controls (CON) based on similar background information to that of the experimental group (Pittsburgh Sleep Quality Index [PSQI] and 17-Item Hamilton Depression Rating Scale [HAMD-17] scores $<7 ; 16-18,19$ a score of $\geq 26$ on the Chinese-Beijing Version of Montreal Cognitive Assessment [MoCA-C] ${ }^{20}$ and no insomnia or related medical history during the same period). The study was approved by the Affiliated Chaohu Hospital of Anhui Medical University Ethics Committee (approval no. 201805-kyxm-01).

\subsection{General data collection}

General information was collected using a questionnaire, which included sex, age, education level, illness duration, medical history and family medical history.

\subsection{Evaluation of sleep quality}

Sleep quality was assessed using the PSQI, which has seven components including subjective sleep quality, sleep latency, sleep duration, habitual sleep efficiency, sleep disturbance, use of sleep medication and daytime dysfunction during the previous month, which are scored on a 4-point rating scale ranging from 0 (none) to 3 ( $\geq 3$ times per week). ${ }^{16}$ In China, a score $\geq 7$ has high diagnostic sensitivity and specificity for distinguishing patients with poor sleep from healthy subjects. ${ }^{18}$ Total PSQI scores range from 0-21, with a higher score corresponding to poorer sleep quality. ${ }^{16}$

\subsection{Assessment of depression severity}

Depression severity was assessed using the HAMD-17, which comprises 17 items relating to depressed mood, feelings of guilt and suicide, sleep, work and activities. ${ }^{19}$ A score $<7$ indicates a healthy state, whereas scores of 7-17, 18-24 and $>24$ correspond to mild, moderate and severe depression, respectively.

\subsection{Cognitive assessment}

The MoCA-C is a widely used cognitive screening tool with good reliability and validity. ${ }^{20}$ The MoCA-C comprises eight dimensions: visual space and executive function, naming, attention, language, abstraction, short-term memory, delayed recall and orientation. ${ }^{21}$ The maximum score is 30 points, and a score $\geq 26$ indicates normal cognitive function. ${ }^{20}$

\subsection{Stigma evaluation}

The Stigma Scale for Chronic Illness (SSCI) is a 24-item measure of stigma, which evaluates the degree of stigma of chronic neurological diseases and includes 13 internalized and 11 enacted items. ${ }^{22}$ Each item is rated using the following response format: $1=$ never, $2=$ rarely, $3=$ sometimes, $4=$ often and $5=$ always. The total score ranges from 24 to 120 points and indicates the severity of stigma suffered by the patient. A score $<8$ indicates a healthy state, whereas scores $>20$ and $>35$ correspond to mild and severe stigma, respectively. ${ }^{22}$

\subsection{Assessment of life quality}

The Medical Outcomes Study (MOS) 36-Item Short-Form Health Survey (SF-36) measures health-related quality of life, functioning and well-being and has strong reliability and validity for use in both general and disease-specific populations. ${ }^{23}$ The survey assesses eight dimensions of health, which include: physical function, physical role, body pain, general health, vitality, social function, emotional role and mental health. It also contains an additional item of health transition, which is not part of any dimension and measures the declared evolution of health. ${ }^{24-25}$ Higher scores correspond to better health-related life quality. 23

\subsection{Statistical analysis}

SPSS version 20 for windows was used for statistical analyses. Continuous normally distributed data are presented as means \pm standard deviations and were evaluated using Student's $t$-test to compare differences between groups and one-way analysis of variance to determine main effects. The least significant difference test was used for multiple comparisons. Non-normally distributed data are expressed as $P 50$ ( $P 25$ and $P 75)$, and differences between groups were analysed using the rank-sum test for two independent samples with a completely randomized design (Mann-Whitney $U$ ). Categorical data were analysed using a chi-squared test. To control for the confounding factors and their influence on the variables, correlations between stigma scores and illness duration (controlling for sex, age and educational level), PSQI score (controlling for sex, age, educational level, illness duration and HAMD-17 score), HAMD-17 score (controlling for sex, age, educational level, illness duration and PSQI score), MoCA-C score (controlling for sex, age, educational level, illness duration, PSQI score and HAMD-17 score) and SF-36 score (controlling for sex, age, educational level, illness duration, PSQI score, HAMD-17 score and MoCA-C score) were assessed using partial correlation analysis. Multiple linear regression was used to explore the correlation between stigma and related influencing factors and identify the contribution of each related influencing factor to changes in stigma. Two-sided $p$ values $\leq 0.05$ were considered statistically significant.

\section{Results}

\subsection{General characteristics of the study subjects}

There were no significant differences in sex ratio $\left(C^{2}=0.8, p=0.4\right)$, age $(U=2235.0, p=0.4)$, or educational level $(U=2840.0, p=0.1)$ between the two groups (Table 1). 
Table 1

Demographic characteristics, sleep quality, depression level and cognitive performance of the study subjects

\begin{tabular}{|c|c|c|c|c|}
\hline Variable & Chronic insomnia disorder & Healthy controls & Statistic & $P$-value \\
\hline Number of cases & 70 & 70 & & \\
\hline Male/female & $21 / 49$ & $26 / 44$ & $C^{2}=0.80$ & 0.4 \\
\hline Age (year) & $50.0(43.0,55.0)$ & $47.0(38.5,54.0)$ & $U=2235.0$ & 0.4 \\
\hline Education (year) & $9.0(6.0,12.0)$ & $9.0(8.8,15.0)$ & $U=2840.0$ & 0.1 \\
\hline Illness duration (year) & $6.0(3.0,13.5)$ & & & \\
\hline PSQI score & $16.0(14.0,17.0)$ & $4.0(3.0,5.0)$ & $U=2485.0$ & $<0.001$ \\
\hline HAMD-17 score & $11.0(7.8,13.0)$ & $2.0(0.0,3.0)$ & $U=69.5$ & $<0.001$ \\
\hline MoCA-C score & $23.0(20.0,26.0)$ & $26.0(26.0,28.0)$ & $U=3997.5$ & $<0.001$ \\
\hline \multicolumn{5}{|c|}{ Normally distributed variables are shown as means \pm standard deviations; non-normally distributed variables are shown as P50 (P25, P75). } \\
\hline
\end{tabular}

\subsection{Sleep quality and depression severity}

PSQI scores differed significantly between groups $(U=2485.0, p<0.001)$, and the CID group had significantly higher scores than the control group. HAMD-17 scores differed significantly between groups $(U=69.5, p<0.001)$; the score of the CID group was almost six times higher than that of the health controls (Table 1).

\subsection{Cognitive function}

There were significant differences in MoCA-C scores between the two groups $(\mathrm{U}=3997.5, p<0.001)$. Patients with CID had significantly lower total MoCA-C scores $(23.0[20.0,26.0])$ than controls $(26.0[26.0,28.0]$; Table 1).

\subsection{Stigma scores}

The ratio of stigma was significantly different between the two groups $\left(C^{2}=35.6, p<0.001\right)$. For performance in stigma, significantly higher scores were observed in patients than controls for the items of total $(U=662.0, p<0.001)$, internalized $(U=593.0, p<0.001)$ and enacted $(U=1568.0, p<0.001)$ stigma scores (Table 2).

Table 2

Stigma and life quality of the study subjects

\begin{tabular}{|c|c|c|c|c|c|}
\hline \multicolumn{2}{|l|}{ Terms } & Chronic insomnia disorder & Healthy controls & Statistic & $P$-value \\
\hline \multicolumn{2}{|l|}{ Stigma (n, \%) } & $57(81.4)$ & $22(31.4)$ & $c^{2}=35.6$ & $<0.001$ \\
\hline \multirow[t]{3}{*}{ SSCl score } & Total & $34.5(26.0,42.3)$ & $24.0(24.0,24.0)$ & $\mathrm{U}=662.0$ & $<0.001$ \\
\hline & Internalized & $21.0(14.0,29.0)$ & $13.0(13.0,13.0)$ & $U=593.0$ & $<0.001$ \\
\hline & Enacted & $12.0(11.0,13.0)$ & $11.0(11.0,12.0)$ & $U=1568.0$ & $<0.001$ \\
\hline \multirow[t]{9}{*}{ SF-36 score } & Physical function & $90.0(85.0,100.0)$ & $95.0(85.0,100.0)$ & $U=2164.0$ & 0.2 \\
\hline & Physical role & $50.0(25.0,100.0)$ & $100.0(50.0,100.0)$ & $U=1560.5$ & $<0.001$ \\
\hline & Body pain & $74.0(62.0,84.0)$ & $84.0(74.0,100.0)$ & $U=1633.5$ & $<0.001$ \\
\hline & General health & $52.1 \pm 22.5$ & $72.9 \pm 18.8$ & $U=1194.0$ & $<0.001$ \\
\hline & Vitality & $55.0(40.0,75.0)$ & $80.0(70.0,85.0)$ & $U=1169.5$ & $<0.001$ \\
\hline & Social function & $77.8(55.6,100.0)$ & $88.9(77.8,100.0)$ & $U=1703.0$ & 0.001 \\
\hline & Emotional role & $66.7(0.0,66.7)$ & $100.0(66.7,100.0)$ & $U=1451.5$ & $<0.001$ \\
\hline & Mental health & $48.0(36.0,72.0)$ & $76.0(67.0,84.0)$ & $U=1147.0$ & $<0.001$ \\
\hline & Health transition & $25.0(25.0,50.0)$ & $50.0(50.0,50.0)$ & $U=1341.0$ & $<0.001$ \\
\hline
\end{tabular}

\subsection{Life quality levels}

There were significant intergroup differences for the SF-36 items of physical role $(U=1560.5, p<0.001)$, body pain $(U=1633.5, p<0.001)$, general health $(U=$ $1194.0, p<0.001)$, vitality $(U=1169.5, p<0.001)$, social function $(U=1703.0, p=0.001)$, emotional role $(U=1451.5, p<0.001)$, mental health $(U=1147.0, p<$ 
0.001) and health transition $(U=1341.0, p<0.001$; Table 2).

\subsection{Correlations among serum cytokine levels, depression severity, sleep quality and cognitive function}

In the CID group, partial correlation analysis showed that illness duration was positively correlated with total $(r=0.62, p<0.001)$, internalized $(r=0.56, p<$ $0.001)$ and enacted stigma scores $(r=0.51, p<0.001)$. For the correlation between PSQI score and stigma (controlling for sex, age, educational level, illness duration and HAMD-17 score) and between HAMD-17 score and stigma (controlling for sex, age, educational level, illness duration and PSQI score), results showed that PSQI $(r=0.28, p=0.02 ; r=0.32, p=0.01)$ and HAMD-17 $(r=0.50, p<0.001 ; r=0.53, p<0.001)$ scores were positively correlated with total and internalized stigma, respectively. Additionally, total stigma scores were negatively correlated with the SF-36 items of vitality $(r=-0.27, p=0.03)$ and mental health ( $r=-0.41, p=0.001)$, after controlling for sex, age, education and MoCA-C scores (Table 3 ). Significant negative correlations were found between internalized stigma and the SF-36 items of physical role $(r=-0.27, p=0.03)$, vitality $(r=-0.33, p=0.001)$ and mental health $(r=-0.45, p<0.001)$.

Table 3

Partial correlations among stigma scores and illness duration, PSQI score, HAMD-17 score and SF-36 score in patients with CID

\begin{tabular}{|c|c|c|c|c|}
\hline \multirow[t]{2}{*}{ Variable } & & \multicolumn{3}{|l|}{ Stigma } \\
\hline & & Total & Internalized & Enacted \\
\hline \multicolumn{2}{|l|}{ Illness duration ${ }^{a}$ (year) } & $0.62^{\star \star}$ & $0.56^{* \star}$ & $0.51^{* *}$ \\
\hline \multicolumn{2}{|l|}{ PSQI ${ }^{b}$ score } & $0.30^{*}$ & $0.34^{\star *}$ & 0.10 \\
\hline \multicolumn{2}{|l|}{ HAMD- $17^{c}$ score } & $0.45^{\star \star}$ & $0.48^{* \star}$ & 0.10 \\
\hline \multicolumn{2}{|l|}{ MoCA-C ${ }^{d}$ score } & -0.06 & -0.08 & 0.004 \\
\hline \multirow[t]{9}{*}{ SF-36 ${ }^{e}$ score } & Physical function & -0.09 & -0.10 & -0.02 \\
\hline & Physical role & -0.22 & $-0.27^{*}$ & -0.02 \\
\hline & Body pain & -0.05 & -0.17 & 0.18 \\
\hline & General health & -0.08 & -0.14 & 0.03 \\
\hline & Vitality & $-0.27^{*}$ & $-0.33^{\star \star}$ & -0.04 \\
\hline & Social function & -0.14 & -0.15 & -0.06 \\
\hline & Emotional role & -0.06 & -0.09 & 0.01 \\
\hline & Mental health & $-0.41^{\#}$ & $-0.45^{\#}$ & -0.19 \\
\hline & Health transition & 0.12 & 0.13 & 0.14 \\
\hline \multicolumn{5}{|c|}{$\begin{array}{l}\text { Notes: }{ }^{a} \text { controlling for sex, age, and educational level; }{ }^{b} \text { controlling for sex, age, educational level, illness duration and HAMD-17; }{ }^{c} \text { controlling for sex, age, } \\
\text { educational level, illness duration and PSQI; }{ }^{d} \text { controlling for sex, age, educational level, illness duration, PSQI and HAMD-17; }{ }^{\mathrm{c}} \text { controlling for sex, age, } \\
\text { educational level, illness duration, PSQI, HAMD-17 and MoCA-C. }{ }^{*} p<0.05 .{ }^{* \star} p<0.01 \text {. }\end{array}$} \\
\hline
\end{tabular}

\subsection{Multiple linear regression between stigma scores and related factors}

For the regression analysis in the CID group, scores for the different items of stigma were defined as the dependent variable and those for all related factors were defined as independent variables based on the partial correlation analysis. Results revealed a significant linear regression, in which illness duration was independently positively correlated with total $(\beta=0.433, p<0.001)$, internalized $(\beta=0.326, p<0.001)$ and enacted $(\beta=0.441, p<0.001)$ stigma scores. The SF36 item of mental health was independently negatively correlated with total $(\beta=-0.346, p=0.007)$ and internalized $(\beta=-0.377, p=0.004)$ stigma (Table 4$)$. 
Table 4

Multiple linear regression between stigma and related influencing factors in patients with CID

\begin{tabular}{|c|c|c|c|c|c|c|c|c|c|c|c|c|c|}
\hline \multirow{2}{*}{\multicolumn{2}{|c|}{ Variable }} & \multicolumn{4}{|l|}{ Total Stigma } & \multicolumn{4}{|c|}{ Internalized Stigma } & \multicolumn{4}{|c|}{ Enacted Stigma } \\
\hline & & $\begin{array}{l}\text { Standardized } \\
\boldsymbol{\beta}\end{array}$ & $t$ & $P$ & $\begin{array}{l}\mathrm{B}(95 \% \\
\mathrm{Cl})\end{array}$ & $\begin{array}{l}\text { Standardized } \\
\boldsymbol{\beta}\end{array}$ & $t$ & $P$ & $\begin{array}{l}\mathrm{B}(95 \% \\
\mathrm{Cl})\end{array}$ & $\begin{array}{l}\text { Standardized } \\
\boldsymbol{\beta}\end{array}$ & $t$ & $P$ & $\begin{array}{l}\mathrm{B}( \\
\mathrm{Cl})\end{array}$ \\
\hline \multicolumn{2}{|c|}{$\begin{array}{l}\text { Illness duration } \\
\text { (year) }\end{array}$} & 0.433 & 5.113 & $<.001$ & $\begin{array}{l}0.357- \\
0.816\end{array}$ & 0.326 & 3.760 & $<.001$ & $\begin{array}{l}0.161- \\
0.527\end{array}$ & 0.441 & 3.841 & 0.000 & $\begin{array}{l}0.1 \\
0.3\end{array}$ \\
\hline \multicolumn{2}{|c|}{ PSQI score } & 0.062 & 0.692 & 0.492 & $\begin{array}{l}-0.457- \\
0.942\end{array}$ & 0.086 & 0.935 & 0.354 & $\begin{array}{l}-0.297- \\
0.818\end{array}$ & 0.035 & 0.285 & 0.777 & $\begin{array}{l}-0 . \\
0.3\end{array}$ \\
\hline \multicolumn{2}{|c|}{ HAMD-17 score } & 0.127 & 1.325 & 0.190 & $\begin{array}{l}-0.192- \\
0.946\end{array}$ & 0.146 & 1.492 & 0.141 & $\begin{array}{l}-0.115- \\
0.792\end{array}$ & -0.048 & -0.366 & 0.716 & $\begin{array}{l}-0 \\
0.2\end{array}$ \\
\hline \multirow{3}{*}{$\begin{array}{l}\text { SF- } \\
36 \\
\text { score }\end{array}$} & $\begin{array}{l}\text { Physical } \\
\text { role }\end{array}$ & -0.128 & -1.484 & 0.143 & $\begin{array}{l}-0.079- \\
0.012\end{array}$ & -0.149 & -1.690 & 0.096 & $\begin{array}{l}-0.067- \\
0.006\end{array}$ & -0.050 & -0.429 & 0.669 & $\begin{array}{l}-0 . \\
0.0\end{array}$ \\
\hline & Vitality & 0.002 & 0.013 & 0.989 & $\begin{array}{l}-0.120- \\
0.122\end{array}$ & -0.015 & -0.122 & 0.903 & $\begin{array}{l}-0.102- \\
0.090\end{array}$ & 0.086 & 0.522 & 0.604 & $\begin{array}{l}-0 . \\
0.0\end{array}$ \\
\hline & $\begin{array}{l}\text { Mental } \\
\text { health }\end{array}$ & -0.346 & -2.775 & 0.007 & $\begin{array}{l}-0.296- \\
0.048\end{array}$ & -0.377 & -2.952 & 0.004 & $\begin{array}{l}-0.244- \\
0.047\end{array}$ & -0.278 & $\begin{array}{l}-1 \\
645\end{array}$ & 0.105 & $\begin{array}{l}-0 . \\
0.0\end{array}$ \\
\hline
\end{tabular}

Abbreviations: HAMD-17, 17-item Hamilton Depression Rating Scale; PSQI, Pittsburgh Sleep Quality Index; SF-36, Medical Outcome Study 36-Item Short-Form Health Survey; CID, chronic insomnia disorder; $\mathrm{Cl}$, confidence interval

\section{Discussion}

\subsection{CID patients have an increased risk of stigma}

As a particularly burdensome personal and social challenge, stigma is closely related to mental disorders, such as depression. ${ }^{26,27}$ Several severe physical disorders are also accompanied by stigmatization. ${ }^{28-30}$ People living with human immunodeficiency virus (HIV) who experience HIV-related stigma are prone to experiencing more depressive symptoms and poorer sleep quality. ${ }^{31}$ Although $50-80 \%$ of individuals with a chronic disease experience stigma at varying levels, ${ }^{32-33}$ little is known about the extent to which stigma impacts chronic insomnia. In the present study, we found that compared with healthy subjects, CID patients had higher stigma ratios and scores. This indicated that CID patients have some degree of stigma, and the level of stigma is significantly higher than that of controls. This may be because stigma exerts a negative influence on sleep due to increased negative self-thought and activation of the ruminative thought process. ${ }^{34-35}$ Indeed, individuals with severe sleep problems are more likely to have depression, which may exacerbate the severity of stigma in CID patients. ${ }^{36}$

\subsection{Lower life quality in CID patients}

Life quality is a major outcome variable in the evaluation of alternative treatments for sleep disorders. ${ }^{37}$ Poor-quality sleep can negatively affect an individual's subjective well-being and quality of life. ${ }^{38}$ Particularly under pathological conditions, high quality of life positively affects sleep. ${ }^{39}$ In the present study, we also found that CID patients had significantly lower scores than controls in most domains of the SF-36, which included physical role, body pain, general health, vitality, social function, emotional role, mental health and health transition, which suggests that CID negatively impacts quality of life. However, we did not find a significant difference in the item of physical function between the two groups. Even in the partial correlation analysis, the item of physical function did not correlate with any of the domains of stigma. Such a discrepancy may be attributed to several factors, such as ethnic origin, sex, comorbidities and differences in the severity of insomnia. ${ }^{40-42}$ Further studies are required to reach a definitive conclusion.

\subsection{Relationship between stigma scores and related influencing factors}

With a prolonged disease course, patients under chronic disease conditions exhibit different levels of stigma. ${ }^{43} \mathrm{~A}$ recent study in high-school students suggested that stigma is strongly and consistently associated with negative psychological health, which includes depressive symptoms and anxiety. ${ }^{44-46}$ However, stigma alleviates throughout the life span as individuals acquire the experience to cope with their surroundings. For instance, in a study in multiple sclerosis (MS) patients by Spencer et al., patients with MS who were particularly concerned and distressed by stigma early in the course of their illness restructured their lives by adapting to the social aspects of their illness, which mitigated the impact of stigma. ${ }^{47}$ In our study, both the partial correlation and multiple linear regression analyses showed that the longer the illness duration, the higher the stigma score, which is in line with previous studies. To gain a comprehensive understanding of stigma changes, it would be meaningful to further observe these populatuons in future studies. Moreover, stigma is influenced not only by illness duration, ${ }^{48-49}$ and identifying other influencing factors is necessary.

Life quality is a critical factor that promotes the progression of stigma. ${ }^{50}$ Individuals with serious mental illness die prematurely by decades, which is not driven by increased suicides or injuries but by poor physical health, which is influenced by stigma. ${ }^{51}$ Our results showed that stigma scores were negatively correlated with most of the subitems of the SF-36, which suggested that stigma in CID patients is related to health quality. Interestingly, the multiple linear regression analysis showed that only the mental health item of the SF-36 was an independent risk factor of stigma, which further demonstrates the influence of mental health on stigma. In other words, mental illness severity should be considered a predictor of stigma among people with mental health problems. ${ }^{52-}$ ${ }^{53}$ This may be because mental disorders, such as depression, affect the perception of the circumstances of daily life. ${ }^{54}$ 
In individuals with mental disorders, stigma may represent a potent stressor that disrupts sleep and impairs health and quality of life ${ }^{55}$ Furthermore, via the content and process of stigma, discrimination has a significant indirect effect on sleep disturbance in these individuals. ${ }^{56}$ In the present study, the partial correlation analysis in the CID patients revealed that poor sleep quality and severe depression were positively correlated with different aspects of stigma, such as total and internalized stigma. However, these correlations were not observed in the subsequent multiple linear regression analysis. These results suggest that in CID patients, the effect of stigma on sleep quality and depression severity is largely dependent on illness duration and life quality, especially mental health.

\section{Conclusion}

Patients with CID had an increased risk of stigma, and illness duration and mental health were the main factors related to stigma. Our results provide a solid foundation to develop and implement interventions for CID patients and suggested that different levels of stigma underlie CID. Caregivers should prioritize monitoring CID patients living with high levels of stigma and developing targeted interventions to eliminate the stigmatization of this group.

\section{List Of Abbreviations}

BMI, body mass index; CID, chronic insomnia disorder; CON, healthy controls; HAMD-17, 17-Item Hamilton Depression Rating Scale; ICSD-3, International Classification of Sleep Disorders, Third Edition; MoCA, Montreal Cognitive Assessment; MoCA-C, Chinese-Beijing Version of Montreal Cognitive Assessment; MOS, Medical Outcomes Study; MS, multiple sclerosis; PSQI, Pittsburgh Sleep Quality Index; SF-36, Medical Outcomes Study Mos 36-Item Short-Form Health Survey; SSCl, Stigma Scale for Chronic Illness.

\section{Declarations}

\section{Ethical approval and consent to participate}

Affiliated Chaohu Hospital of Anhui Medical University Ethics Committee (approval no. 201805-kyxm-01). All participants who met the inclusion and exclusion criteria were informed of all essential information regarding the research project, and we obtained a signed informed consent form before the interviews.

\section{Consent for publication}

Not applicable.

\section{Available of data and materials}

Not applicable.

\section{Competing interests}

The authors declare no conflicts of interest.

\section{Role of funding sources}

This work was financially supported by the National Natural Science Foundation of China (grant no. 81671316) and the Natural Science Foundation of Anhui Medical University (grant nos. 2020xkj053 and 2018xkj066). These funding sources had no role in the study design, analysis, data interpretation or decision to submit the article for publication.

\section{Authors' contributions}

Gui-Hai Chen and Hui-Qin Sun conceived, designed, and supervised the study. Shuo He and Xue-Jia Ke performed statistical analyses and drafted the manuscript. Yun Wang and Deng-Zhi Xia participated in project supervision. Yan Wu, Xiao-Yi Kong and Ping Zhang collected and organized the data. All authors read and approved the final manuscript.

\section{Acknowledgements}

We would like to thank all patients who participated in our study.

\section{References}

1. Martínez-Fernández A, Rueda Vega M, Quintas S, de Toledo Heras M, Díaz de Terán J, Latorre González G, et al. Psychosocial repercussion of migraine: Is it a stigmatized disease? Neurological Sciences: official journal of the Italian Neurological Society of the Italian Society of Clinical Neurophysiology. 2020;41(8):2207-13. doi:10.1007/s10072-020-04332-6.

2. Rao D, Choi SW, Victorson D, Bode R, Peterman A, Heinemann A, et al. Measuring stigma across neurological conditions: The development of the stigma scale for chronic illness (SSCI). Qual Life Res. 2009;18(5):585-95. doi:10.1007/s11136-009-9475-1.

3. Naushad N, Dunn LB, Muñoz RF, Leykin Y. Depression increases subjective stigma of chronic pain. J Affect Disord. 2018;229:456-62. doi:10.1016/j.jad.2017.12.085. 
4. Hankir AK, Northall A, Zaman R. (2014). Stigma and mental health challenges in medical students. BMJ Case Reports, 2014, 205-226. doi:10.1136/bcr2014-205226.

5. World Health Organization Depression (2018). Depression. http://www.who.int/mediacentre/factsheets/fs369/en/. Accessed 2 April 2018.

6. Angermeyer MC, van der Auwera S, Carta MG, Schomerus G. Public attitudes towards psychiatry and psychiatric treatment at the beginning of the $21 \mathrm{st}$ century: A systematic review and meta-analysis of population surveys. World Psychiatry. 2017;16(1):50-61. doi:10.1002/wps.20383.

7. Boerema AM, Kleiboer A, Beekman AT, van Zoonen K, Dijkshoorn H, Cuijpers P. Determinants of help-seeking behavior in depression: a cross-sectional study. BMC Psychiatry. 2016;16:78. doi:10.1186/s12888-016-0790-0.

8. Chen JA, Shapero BG, Trinh NT, Chang TE, Parkin S, Alpert JE, et al. Association between stigma and depression outcomes among Chinese immigrants in a primary care setting. J Clin Psychiatry. 2016;77(10):e1287-92. doi:10.4088/JCP.15m10225.

9. Hertenstein E, Feige B, Gmeiner T, Kienzler C, Spiegelhalder K, Johann A, et al. Insomnia as a predictor of mental disorders: A systematic review and metaanalysis. Sleep Med Rev. 2019;43:96-105. doi:10.1016/j.smrv.2018.10.006.

10. Pigeon WR, Bishop TM, Krueger KM. Insomnia as a precipitating factor in new onset mental illness: A systematic review of recent findings. Current Psychiatry Reports. 2017;19(8):44. doi:10.1007/s11920-017-0802-x.

11. Chen PJ, Huang CL, Weng SF, Wu MP, Ho CH, Wang JJ, et al. Relapse insomnia increases greater risk of anxiety and depression: Evidence from a population-based 4-year cohort study. Sleep Med. 2017;38:122-9. doi:10.1016/j.sleep.2017.07.016.

12. Riemann D, Krone LB, Wulff K, Nissen C. Sleep, insomnia, and depression. Neuropsychopharmacology. 2020;45(1):74-89. doi:10.1038/s41386-019-0411$y$.

13. Wang Z, Dang J, Zhang X, Moore JB, Li R. Assessing the relationship between weight stigma, stress, depression, and sleep in Chinese adolescents. Qual Life Res. 2021;30(1):229-38. doi:10.1007/s11136-020-02620-4.

14. He S, Chen XX, Ge W, Yang S, Chen JT, Niu JW, et al. Are anti-inflammatory cytokines associated with cognitive impairment in patients with insomnia comorbid with depression? A pilot study. Nature Science of Sleep. 2021;13:989-1000. doi:10.2147/NSS.S312272.

15. Morin CM, Drake CL, Harvey AG, Krystal AD, Manber R, Riemann D, et al. Insomnia disorder. Nature Reviews Disease Primers. 2015;1:1-18. doi:10.1038/nrdp.2015.26.

16. Carpenter JS, Andrykowski MA. Psychometric evaluation of the Pittsburgh Sleep Quality Index. J Psychosom Res. 1998;45:5-13. doi:10.1016/S00223999(97)00298-5.

17. Mollayeva T, Thurairajah P, Burton K, Mollayeva S, Shapiro CM, Colantonio A. The Pittsburgh sleep quality index as a screening tool for sleep dysfunction in clinical and non-clinical samples: A systematic review and meta-analysis. Sleep Med Rev. 2016;25:52-73. doi:10.1016/j.smrv.2015.01.009.

18. Tsai PS, Wang SY, Wang MY, Su CT, Yang TT, Huang CJ, et al. Psychometric evaluation of the Chinese version of the Pittsburgh Sleep Quality Index (CPSQI) in primary insomnia and control subjects. Qual Life Res. 2005;14(8):1943-52. doi:10.1007/s11136-005-4346-x.

19. Hamilton M. A rating scale for depression. J Neurol Neurosurg Psychiatry. 1960;23:56-62. doi:10.1136/jnnp.23.1.56.

20. Chen X, Zhang R, Xiao Y, Dong J, Niu X, Kong W. Reliability and validity of the Beijing version of the Montreal Cognitive Assessment in the evaluation of cognitive function of adult patients with OSAHS. PLoS One. 2015;10:1-12. doi:10.1371/journal.pone.0132361.

21. Hsu JL, Fan YC, Huang YL, Wang J, Chen WH, Chiu HC, et al. Improved predictive ability of the Montreal Cognitive Assessment for diagnosing dementia in a community-based study. Alzheimer's Research Therapy. 2015;7:69. doi:10.1186/s13195-015-0156-8.

22. Rao D, Choi SW, Victorson D, Bode R, Peterman A, Heinemann A, et al. Measuring stigma across neurological conditions: the development of the stigma scale for chronic illness (SSCI). Qual Life Res. 2009;18(5):585-95. doi:10.1007/s11136-009-9475-1.

23. Ware JE Jr. SF-36 health survey update. Spine. 2000;25(24):3130-9. doi:10.1097/00007632-200012150-00008.

24. Ware J, Snow K, Kosinski M, Gande B. SF-36 health survey: Manual and interpretation guide. Boston: New England Medical Center; 1993.

25. Alonso J, Prieto L, Antó JM. The Spanish version of the SF-36 health survey (the SF-36 health questionnaire): An instrument for measuring clinical results. Med Clin. 1995;104:771-6.

26. Lynch H, McDonagh C, Hennessy E. Social anxiety and depression stigma among adolescents. J Affect Disord. 2021;281:744-50. doi:10.1016/j.jad.2020.11.073.

27. Busby Grant J, Bruce CP, Batterham PJ. Predictors of personal, perceived and self-stigma towards anxiety and depression. Epidemiological Psychiatric Sciences. 2016;25(3):247-54. doi:10.1017/S2045796015000220.

28. Ballouz T, Gebara N, Rizk N. HIV-related stigma among health-care workers in the MENA region. Lancet HIV. 2020;7(5):e311-3. doi:10.1016/S23523018(19)30401-1.

29. Rubino F, Puhl RM, Cummings DE, Eckel RH, Ryan DH, Mechanick Jl, et al. Joint international consensus statement for ending stigma of obesity. Nat Med. 2020;26(4):485-97. doi:10.1038/s41591-020-0803-x.

30. Johnson JL, Campbell AC, Bowers M, Nichol AM. (2007). Understanding the social consequences of chronic obstructive pulmonary disease: The effects of stigma and gender. Proceedings of the. American Thoracic Society, 4(8), 680-682. doi:10.1513/pats.200706-084SD.

31. Fekete EM, Williams SL, Skinta MD. Internalised HIV-stigma, loneliness, depressive symptoms and sleep quality in people living with HIV. Psychology Health. 2018;33(3):398-415. doi:10.1080/08870446.2017.1357816.

32. Harper KJ, Osborn CY, Mayberry LS. Patient-perceived family stigma of Type 2 diabetes and its consequences. Families Systems Health. 2018;36(1):1137. doi:10.1037/fsh0000316. 
33. Sarfo FS, Nichols M, Qanungo S, Teklehaimanot A, Singh A, Mensah N, et al. Stroke-related stigma among West Africans: Patterns and predictors. Journal of Neurological Sciences. 2017;375:270-4. doi:10.1016/j.jns.2017.02.018.

34. Chan KKS, Fung WTW. The impact of experienced discrimination and self-stigma on sleep and health-related quality of life among individuals with mental disorders in Hong Kong. Qual Life Res. 2019;28(8):2171-82. doi:10.1007/s11136-019-02181-1.

35. Jackson DB, Testa A, Vaughn MG, Semenza DC. Police stops and sleep behaviors among at-risk youth. Sleep Health. 2020;6(4):435-41. doi:10.1016/j.sleh.2020.02.006.

36. Levenson JC, Thoma BC, Hamilton JL, Choukas-Bradley S, Salk RH. Sleep among gender minority adolescents. Sleep. 2021;44(3):zsaa185. doi:10.1093/sleep/zsaa185.

37. Reimer MA, Flemons WW. Quality of life in sleep disorders. Sleep Med Rev. 2003;7(4):335-49. doi:10.1053/smrv.2001.0220.

38. Olfson M, Wall M, Liu SM, Morin CM, Blanco C. Insomnia and Impaired Quality of Life in the United States. J Clin Psychiatry. 2018;79(5):17m12020. doi:10.4088/JCP.17m12020.

39. Zhang Y, Cui C, Wang Y, Wang L. Effects of stigma, hope and social support on quality of life among Chinese patients diagnosed with oral cancer: a crosssectional study. Health Quality of Life Outcomes. 2020;18(1):112. doi:10.1186/s12955-020-01353-9.

40. Espie CA, Emsley R, Kyle SD, Gordon C, Drake CL, Siriwardena AN, et al. Effect of digital cognitive behavioral therapy for insomnia on health, psychological well-being, and sleep-related quality of life: A randomized clinical trial. JAMA Psychiatry. 2019;76(1):21-30. doi:10.1001/jamapsychiatry.2018.2745.

41. Pengo MF, Won CH, Bourjeily G. Sleep in women across the life span. Chest. 2018;154(1):196-206. doi:10.1016/j.chest.2018.04.005.

42. Morin CM, Belleville G, Bélanger L, Ivers $\mathrm{H}$. The Insomnia Severity Index: Psychometric indicators to detect insomnia cases and evaluate treatment response. Sleep. 2011;34(5):601-8. doi:10.1093/sleep/34.5.601.

43. Tomiyama AJ, Carr D, Granberg EM, Major B, Robinson E, Sutin AR, et al. How and why weight stigma drives the obesity 'epidemic' and harms health. BMC Med. 2018;16(1):123. doi:10.1186/s12916-018-1116-5.

44. Lanfredi M, Macis A, Ferrari C, Rillosi L, Ughi EC, Fanetti A, et al. Effects of education and social contact on mental health-related stigma among highschool students. Psychiatry Res. 2019;281:112581. doi:10.1016/j.psychres.2019.112581.

45. Gonzalez BD, Jacobsen PB. Depression in lung cancer patients: The role of perceived stigma. Psychooncology. 2012;21(3):239-46. doi:10.1002/pon.1882.

46. Kissane DW, Patel SG, Baser RE, Bell R, Farberov M, Ostroff JS, et al. Preliminary evaluation of the reliability and validity of the Shame and Stigma Scale in head and neck cancer. Head Neck. 2013;35(2):172-83. doi:10.1002/hed.22943.

47. Spencer LA, Silverman AM, Cook JE. Adapting to multiple sclerosis stigma across the life span. International Journal of MS Care. 2019;21(5):227-34. doi:10.7224/1537-2073.2019-056.

48. Johnco C, Rapee RM. Depression literacy and stigma influence how parents perceive and respond to adolescent depressive symptoms. J Affect Disord. 2018;241:599-607. doi:10.1016/j.jad.2018.08.062.

49. Yuan JM, Zhang JE, Zheng MC, Bu XQ. Stigma and its influencing factors among Chinese patients with stoma. Psychooncology. 2018;27(6):1565-71. doi:10.1002/pon.4695.

50. Hearn M, Whorwell PJ, Vasant DH. Stigma and irritable bowel syndrome: A taboo subject? Lancet Gastroenterology Hepatology. 2020;5(6):607-15. doi:10.1016/S2468-1253(19)30348-6.

51. The Lancet. The health crisis of mental health stigma. Lancet. 2016;387(10023):1027. doi:10.1016/S0140-6736(16)00687-5.

52. Mejia-Lancheros C, Lachaud J, O'Campo P, Wiens K, Nisenbaum R, Wang R, et al. Trajectories and mental health-related predictors of perceived discrimination and stigma among homeless adults with mental illness. PLoS One. 2020;15(2):e0229385. doi:10.1371/journal.pone.0229385.

53. Szcześniak D, Kobyłko A, Wojciechowska I, Kłapciński M, Rymaszewska J. Internalized stigma and its correlates among patients with severe mental illness. Neuropsychiatric Disease Treatment. 2018;14:2599-608. doi:10.2147/NDT.S169051.

54. Kent L, Van Doorn G, Klein B. Time dilation and acceleration in depression. Acta Physiol (Oxf). 2019;194:77-86. doi:10.1016/j.actpsy.2019.02.003.

55. Slopen N, Lewis TT, Williams DR. Discrimination and sleep: A systematic review. Sleep Med. 2016;18:88-95. doi:10.1016/j.sleep.2015.01.012.

56. Chan KKS, Fung WTW. The impact of experienced discrimination and self-stigma on sleep and health-related quality of life among individuals with mental disorders in Hong Kong. Qual Life Res. 2019;28(8):2171-82. doi:10.1007/s11136-019-02181-1. 